\title{
A preliminary study on the Evaluation Index of Green Service area under the concept of New Green Building Evaluation Standard
}

\author{
Liu Jun ${ }^{1,2}$, Liu Chunfeng ${ }^{3}$, Peng Fang ${ }^{4}$, Zhao Jing ${ }^{*}$ \\ ${ }^{1}$ School of civil engineering, Shandong University, Jinan, 250061; \\ ${ }^{2}$ Jiangxi Provincial Expressway Investment Group Co. Ltd, Nanchang, 330025 \\ ${ }^{3}$ Jiangxi Vocational and Technical College of Communications, Nanchang, 330013 \\ ${ }^{4}$ School of Information and Engineering, Jiangxi Agricultural University, Nanchang, 330045 \\ ${ }^{5}$ Research Institute of Highway Ministry of Transport, Bei jing, 100088, China
}

\begin{abstract}
ABSRTACT: This paper compares the evaluation standards of new and old green buildings, and studies the existing evaluation system of Expressway Green Service area, this paper expounds the relationship between the existing Green Service area evaluation system and the new and old green building standards, and finally, combining the new green building evaluation standards and the actual evaluation work, advances the new Green Service Area Evaluation Index, it will guide the revision of the relevant policy standard of the current Green Service area.
\end{abstract}

\section{Development of green building evaluation}

As an artificial environment, the impact of architecture on the ecological environment is multi-level and multi-faceted, among which the architecture with clear goals and means of ecological environmental protection can be called green building, so Green building is also called ecological building, sustainable building [1]. In August 2004, the Ministry of Construction Defined Green Building as: providing people with healthy, comfortable and safe living, working and activity space, at the same time in the building life cycle (material production, building planning, design, construction, operation and maintenance and demolition, recycling process) to achieve high efficiency in the use of resources (energy, land, water, material), the minimum impact on the environment of the building, that is to say, the requirements of environmental protection should be fully taken into account in the design, construction and use of buildings, and buildings should be closely integrated with environmental protection, high and new technologies, energy and so on, capable of contributing to the physical and mental well-being of users and of creating work and living space structures that meet environmental protection requirements [1]. The concept of green building is the concrete embodiment of the current global sustainable development strategy in the field of architecture. Due to the differences of region, concept and technology, there is no uniform definition of green building at home and abroad. On the technical level, green building should consider the following key issues: energy, emissions, water use, land use, impact on regional ecology and indoor air quality, etc. At the same time, we should consider the function and aesthetic significance of the architecture.

The practice of green building is undoubtedly a highly complex systems engineering, requiring architects not only to have an ecological concept, but also to adopt a corresponding design methodology, also needs the management, the construction unit to have the strong environmental protection consciousness. The intervention of this multi-level cooperative relationship needs to establish a clear evaluation and certification system in the whole process, and check the effect of the ecological goal of architectural design in a quantitative way, with certain indicators to measure the degree of achievement of the expected environmental performance. The Evaluation System Not only guides and inspects green building practices, but also provides constraints and norms for the construction market, prompting more consideration of environmental factors in the design, operation, management and maintenance process, guide the building to energy-saving, environmental protection, health and comfort, efficiency-oriented track development. In recent 10 years, some developed countries in the world have launched their own different methods of architectural environmental assessment.

The evaluation mechanism used in the evaluation of green ecological buildings in different countries is not completely the same, generally including the following three aspects: first, to determine the evaluation index project, that is, according to the local natural environment (such as regional demand, climate factors, green type, etc.) , as well as architectural factors

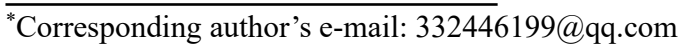


(including architectural form, development stage, regional practice, etc.) , establishing a detailed framework for the construction evaluation indicator projects to be applied locally; secondly, establishing evaluation criteria for each indicator project established above, which may be qualitative or quantitative, however, existing national or regional norms and generally accepted international standards are used as the most important references and guidelines. Third, when conducting evaluations, experts are organized to prepare projects that are not covered by existing norms, taking into account the actual level and needs of regional practice.

China's Green Building Standard System was established in 2006, the first edition of "Green building evaluation standards" (GB/T 50378-2006) was officially released and put into effect, the definition, connotation, technical specifications and evaluation standards of green building in China [2], to provide guidance for China's green building construction, and promote China's green building and related technology, standards development. Since the release of the first edition in 2006, the standard has undergone more than 10 years of "3 edition 2 revision", 2014 revision [3], its index system was revised to be composed of seven indexes, such as "land-saving and outdoor environment, energy-saving and energy utilization, water-saving and water resources utilization, material-saving and material resources utilization, indoor environmental quality, construction management and operation management", each kind of index includes control items and grading items, and the index system also sets up additional items to encourage the improvement and innovation of green building technology and management, and its evaluation is divided into design evaluation and operation evaluation.

At present, according to the Ministry of Housing and Urban-Rural Development of the People's Republic of China announcement no. 61 of 2019, the National Standard "Green Building Evaluation Standard" GB/T50378-2019[4] will be formally implemented from August 1. The "New Standard", as the fundamental technical standard for standardizing and leading the development of green buildings in China, reconstructs the technical index system of green building evaluation, divided into "safe and durable, healthy and comfortable, convenient life, resource conservation, livable environment, improvement and innovation" several aspects, in response to the national strategy of ecological civilization and the basic strategy of upholding and developing socialism with Chinese characteristics in the new era, "insisting on the harmonious coexistence of man and nature", the construction of socialist ecological civilization has entered a new realm.

Compared with the 2014 edition, the 2019 edition of the New Standard embodies the General Secretary Xi's basic strategy of developing harmonious coexistence between man and nature in the new era of socialism with Chinese characteristics, the original definition of green building is "a building that can save resources (energy, land, water and materials), protect environment, reduce pollution, provide healthy, applicable and efficient space for people, and live in harmony with nature", to read "in the life cycle, save resources, protect the environment, reduce pollution, to provide people with health, applicable, efficient use of space, to maximize the harmonious coexistence of man and nature of high-quality buildings. ". The New Standard Evaluation Technical Index System starts from the "people-oriented" construction performance, transforms the developer's angle of view to the user's angle of view, designs from the resident's angle of view, in order to enhance the building user's experience and the sense of obtaining to the green building. From the original "from the 'four sections one environmental protection' as well as construction management, Operation Management Framework Score", into "safe and durable, healthy and comfortable, convenient life, resource conservation, livable environment" five indicator system, and "improve and innovation" a major plus. The rating of the new standard has been changed from three stars to four-segment stars, and a new "basic level" has been added, adding mandatory technical requirements for different star levels. The basic level is to meet all control requirements, control and full text of the effective link Peremptory norm, will be the full implementation of green building standards as the main basis, with the major international green building evaluation standards. The New Standard has higher requirements for the integrated design of civil construction and decoration, and durability has become an important grading index. The Indoor air quality grading items become heavier, and the total score of BIM technology application evaluation is increased to 15 points, therefore 2019 new standards for construction enterprises higher requirements, construction enterprises to undertake green building projects, must have the corresponding technical conditions and talent, to be able to meet the requirements.

\section{The development of Green Service area evaluation in China}

As a kind of green building, the standard of construction and evaluation of Green Service area is derived from the standard of green building. First of all, based on GB/T50378-2014, and according to the characteristics of the construction and operation management of the Highway Service area, this paper studies and formulates the Transportation Industry Standard "technical requirements for Green Transportation Facilities Assessment Part 2: Green Service Areas"(JT/T 1199.2-2018) [5], and puts forward the contents and methods of specific assessment for Green Service Areas Assessment of expressway in China, this standard evaluates the green service areas according to the seven categories of "land-saving and outdoor environment, energy-saving and energy utilization, water-saving and water resources utilization, material-saving and material resources utilization, environmental protection, Green Service and safeguard measures", which will play an important role in guiding the evaluation of the Green Service areas in China. Sentence is too long, please 
supply a shorter sentence. The standard introduces the green construction of the Green Service area from the aspects of site selection, site planning, housing construction, energy-saving system, water-saving system, environmental protection facilities, landscape and greening, green service.

Overall, the 2018 Ministry of Transport of the People's Republic of China Technical Requirements for Green Transport Facilities Assessment Part 2: Green Service areas is based on the 2014 edition of Green Building Assessment Standards in the framework of the indicator evaluation system, taking "four sections and one environmental protection" as the core content and combining with the characteristics of the highway service area, some modifications have been made. When it is applied to the evaluation of the service area, more consideration is given to the greening of the building itself and the conservation of resources, and the "people-oriented" evaluation requirement is not fully reflected, at the same time did not reflect the service area industry modernization, sponge, health and the application of BIM technology in recent years to promote some of the new architectural concepts. The 2014 edition of Green building standards does not reflect "high-quality buildings, " construction units, operating units can not feel the advantages of green buildings in health, comfort, convenience, livable and so on. In contrast, the local standard of Anhui Province — A guide to the construction of a Green Service area -- has incorporated the concepts of improving service, health, comfort, and living in harmony with nature, however, the specific construction technology still focuses on the conventional technologies such as land-saving, energy-saving, water-saving, material-saving, environmental protection, and so on.

The newly released "Green building evaluation standard" GB/T50378-2019 puts forward the higher requirement of "high-quality building with maximum harmonious coexistence between man and nature", which also puts forward a new guiding ideology for the evaluation of Green Service area. We can see that the new standards embody the General Secretary Xi's basic policy of developing harmonious coexistence between man and nature in the new era of socialism with Chinese characteristics, from emphasizing "maximum saving of resources (energy, land, water and materials) , environmental protection"(four sections and one environmental protection) to "harmonious coexistence between man and nature", aiming at high-quality buildings, from "land-saving and outdoor environment, energy-saving and energy utilization, water-saving and water resources utilization, material-saving and material resources utilization, indoor environmental quality, construction management, Operation Management", the five index systems of "safe and durable, healthy and comfortable, convenient life, resource-saving, environment livable" and "improvement and innovation", one additional item. Comparatively speaking, the assessment standards of Green Service areas promulgated and implemented in China have not yet reflected these core changes, and green service areas as a kind of buildings, these changes of new building standards also put forward new and higher requirements for the research and establishment of evaluation index and Standard System of green service area in transportation industry.

Based on the analysis and research, this paper summarizes the research results of green building evaluation system that some scholars have at home and abroad, and takes some newly issued green building evaluation standards in China as the basis, combined with the special use function of the expressway service area, taking "harmonious coexistence of man and nature" as the guiding ideology, and combining the local physical geography and climate characteristics, the evaluation method of "maximum saving of resources (energy, land, water and materials) and environmental protection"(four sections and one environmental protection) is changed to "maximum realization of harmonious coexistence of human and nature with high-quality service facilities", the Evaluation Index System of Green Service area is reconstructed to provide reference and basis for revising the construction evaluation standard of green service area in the next stage.

\section{Based on the newly revised "green building evaluation standards" to build a new green service area evaluation index framework}

Based on the above research, the primary and Secondary Index frame and the basic control item requirements of the new service area based on the new "green building evaluation standard" are as follows:

\subsection{Level 1 indicators}

Considering that the first-level index is focused on the concept of green building and the service area is one kind of buildings with prominent functional characteristics, the first-level index of this evaluation system is based on the latest "Green Building Evaluation Standard" of our country macroscopically, the project establishes 5 level 1 indicators and 1 Innovation Plus, level 1 indicators are: Safety and durability, health and comfort, service efficiency, resource conservation, environmental friendliness and innovation plus.

\subsection{Secondary Indicators}

\subsubsection{Safe and durable}

Safety and durability are divided into two secondary indexes: Safety and durability based on the Green Service area which meets the requirements of site, structural bearing capacity, building use function, external service facilities, emergency evacuation requirements and safety guidance and protection.

Among them, safety includes: Seismic Damping performance, safety protection measures, site anti-skid measures, site lighting measures. 
Durability includes: The service area of building flexibility, parts durability, building structural materials durability, decorative building materials durability.

\subsubsection{Health and comfort}

Health and comfort in meeting the "indoor air quality standards" Gb/t 18883, "sanitary standards for drinking water" GB 5749, "civil building sound insulation design code" GB 50118, "building lighting design standards"
GB 50034, "LED indoor lighting application technical requirements" $\mathrm{Gb} / \mathrm{t}$ 31831, "civil building heating, ventilation and air conditioning design code" GB 50736, "civil building thermal design code" GB 50176 basis, divided into indoor air quality, water quality, sound environment, light environment, indoor humid and thermal environment 5 secondary indicators, see figure 1.

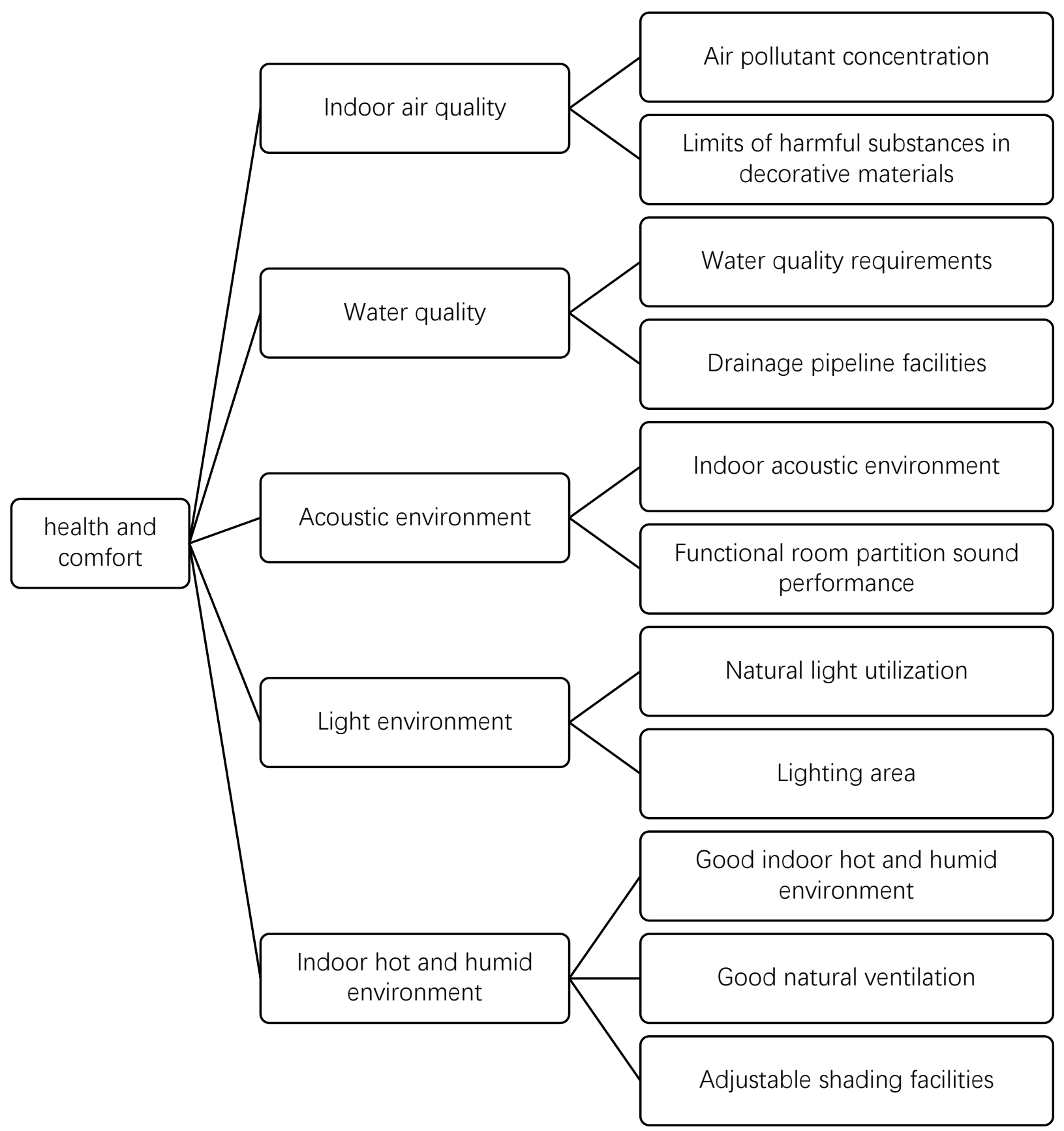

Figure 1. secondary indicators of Health and comfort 


\subsubsection{Efficient service}

The service is efficient on the basis of meeting the continuous barrier-free walkways, electric vehicle charging facilities and barrier-free parking spaces, automatic monitoring systems and information network systems between the buildings, outdoor venues, public green areas, gas stations, etc. in the service area, it is divided into 4 Secondary Indexes: Transportation Organization, service facilities, intelligent operation and management guarantee, as shown in figure 2.

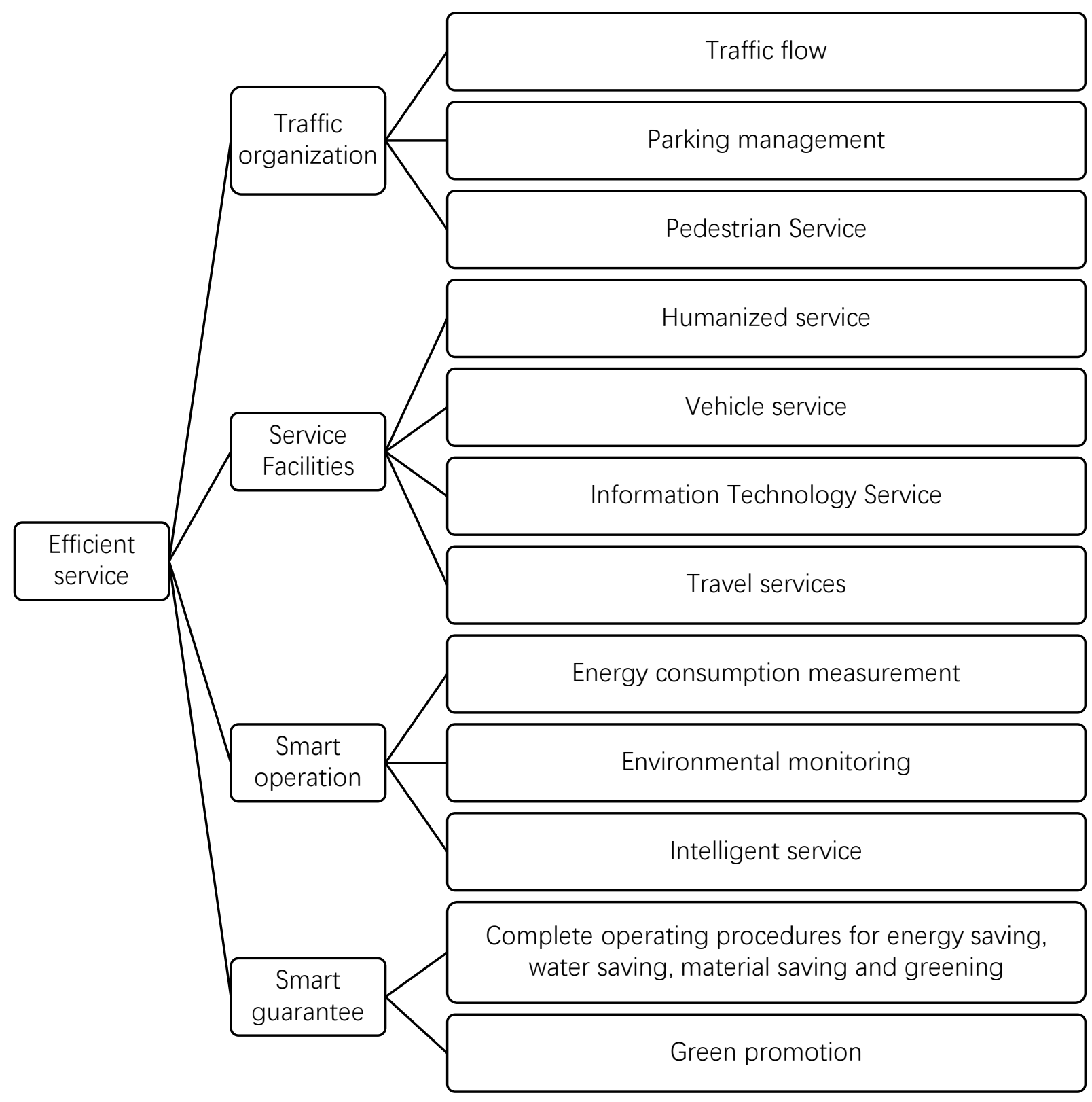

Figure 2. SECONDARY INDICATORS OF SERVICE EFFICIENCY

\subsubsection{Resource conservation}

Resource Conservation should be based on the combination of natural conditions and the functions of the service area, taking into account heating, air conditioning, lighting, cold and heat sources, transmission and distribution systems, water resources recycling, building structure, shape and materials, etc., divided into land and land use, energy and energy use, water and resource use, material and Green Building Materials 4 secondary indicators, see figure 3 . 


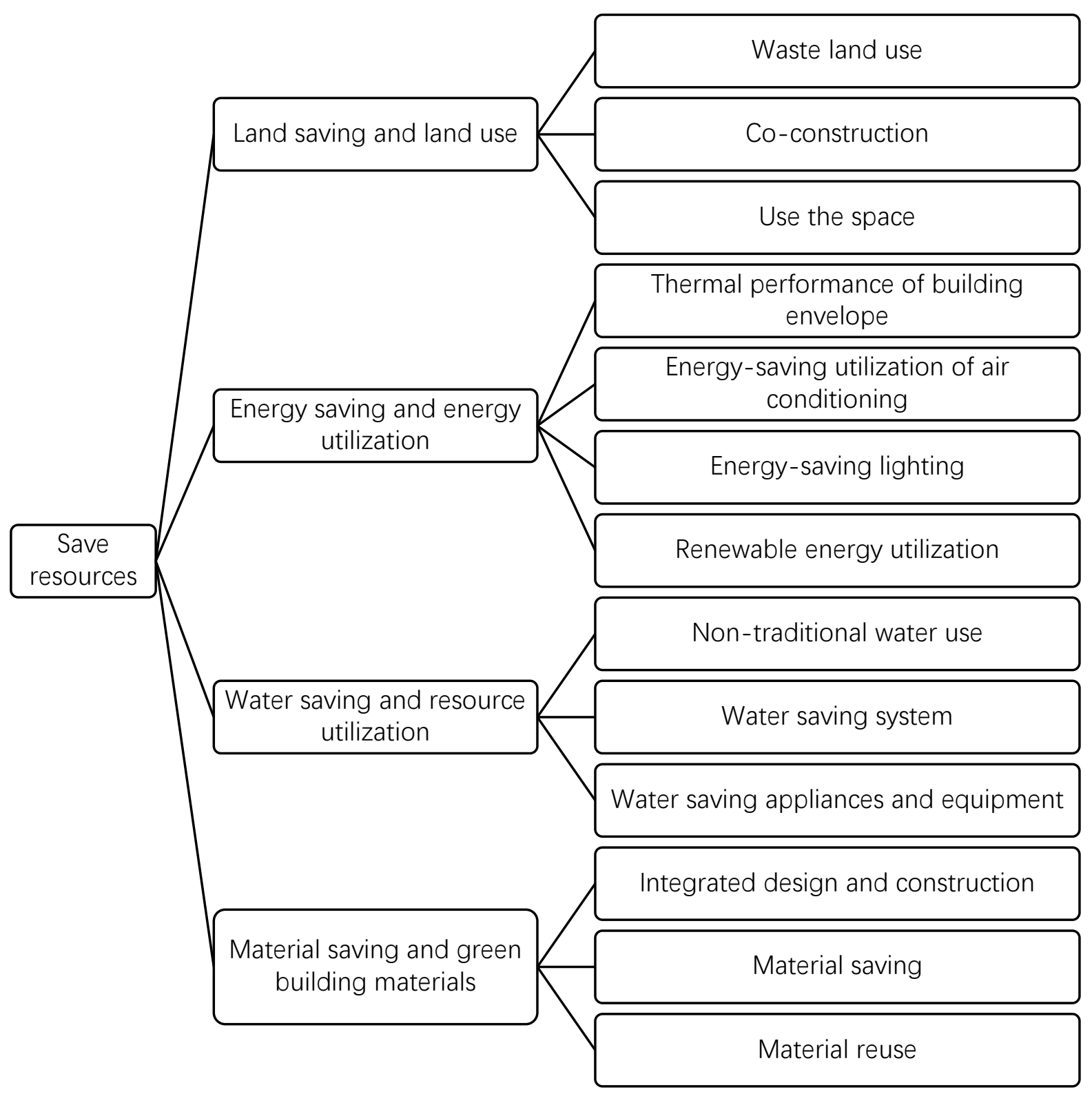

Figure 3. secondary indicators for resource efficiency

\subsubsection{Environmentally friendly}

Environmental friendliness should be based on consideration of architectural layout of the service area, outdoor thermal environment, green coverage of the service area, Site sponge, guidance and marking system, pollution source emission control, waste classification treatment and landscape integration, divided into site ecology and landscape, outdoor physical environment 2 secondary indicators, see figure 4 . 


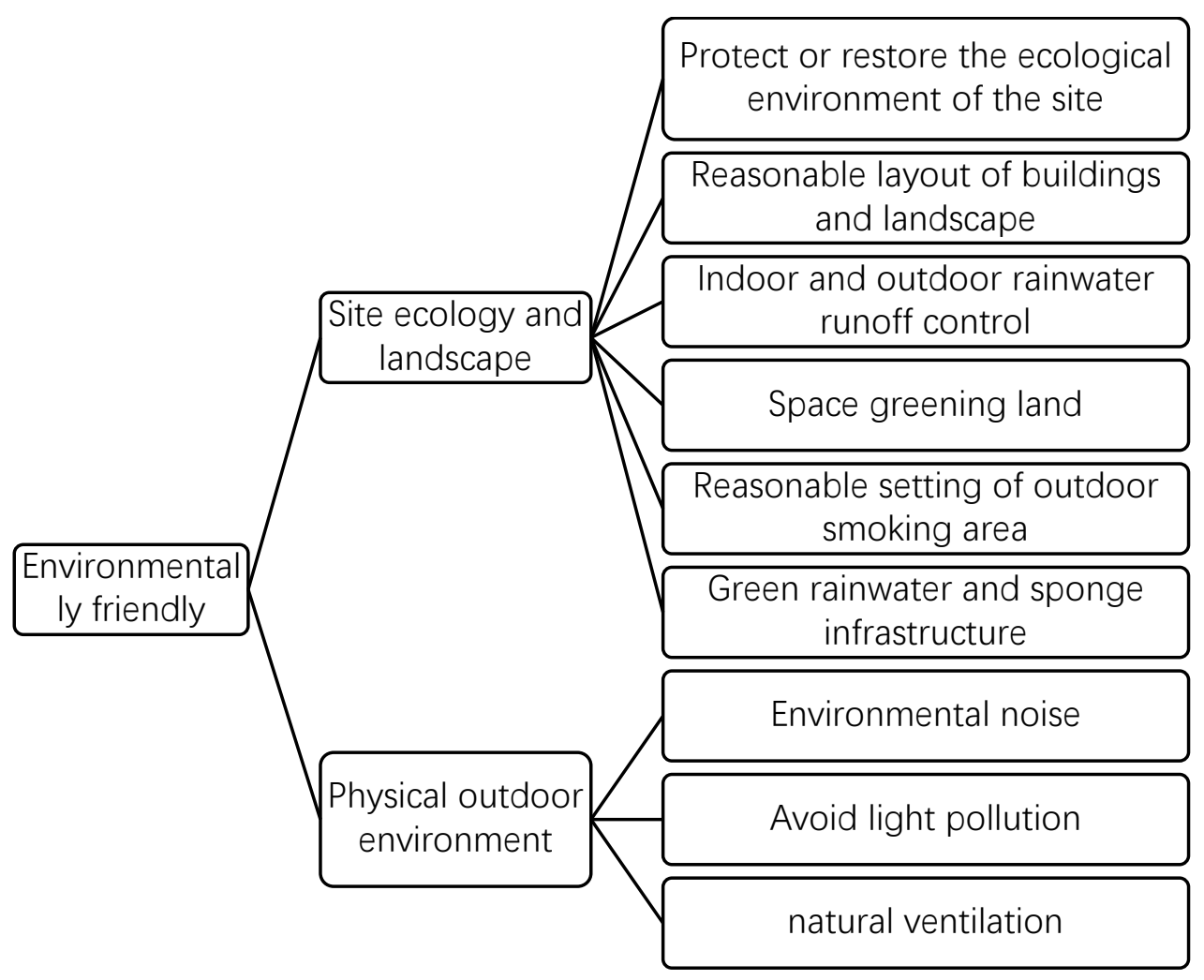

Figure 4. environmentally friendly secondary indicators

\subsubsection{Enhancement and innovation}

Green Service area improvements and innovations are reflected in:

- Use BIM technology for design, construction and management;

- Installing counting equipment for entering vehicles, setting speed limit signs and speed detection and display system on the ramps entering the service area;

- Adopting other innovative technological measures to save energy and resources, protect the ecological environment and ensure safety and health, and the benefits are obvious;

- adopt the architectural style and feature design with suitable regional characteristics, and inherit the regional architectural culture according to the local conditions.

\subsection{Basic controls}

The basic control items of green service area assessment belong to five categories, and the assessment result of control items should be up to or down to the standard. The service area must meet the requirements of the control conditions. If any conditions are not met, the service area is ineligible for assessment of the Green Service area.

\subsubsection{Safe and durable}

- Implement the responsibility system for production safety, formulate the service area fire safety system, hazardous chemicals accidents and other emergency plans.

- The facilities and equipment in service area are running normally and the running record is complete.

- The quality of construction project should conform to JTG F80/1 and GB 50300, and the grade of the service area is qualified.

\subsubsection{Health and comfort}

- The construction of the service area is forbidden to use the building materials and products which are forbidden and restricted by the state and the locality, and the indoor environment is up to the relevant regulations of $\mathrm{Gb} / \mathrm{t} 18883$.

- when using self-contained well water sources for water supply in service areas, the use of groundwater shall be approved by the local water authority, and the quality of water supply shall meet the requirements of GB 5749.

- The emission of exhaust gas pollutants produced in the operation process shall meet the requirements of GB 13271, GB 18483 and other relevant standards.

- the discharge of sewage from the service area into the municipal pipe network system shall meet the requirements of CJ 343; when it can 
not be discharged into the municipal pipe network, sewage treatment facilities shall be constructed, the quality of the discharge water shall meet the requirements of GB 8978, and when there are local water pollutant discharge standards, must meet local standards.

\subsubsection{Efficient service}

- The traffic organization in the service area is reasonable, the main traffic flow should not be crossed or reversed, and the special parking spaces should not be intermingled with other parking spaces.

- The barrier-free design of service area meets the requirements of GB 50763.

\subsubsection{Resource conservation}

- The service area does not use the electric direct heating equipment as the heating heat source and the air humidification heat source of the heating and air conditioning system.

- The energy consumption of cold and heat source, transmission and distribution system and lighting in service area should be measured separately and equipped with corresponding energy consumption measuring equipment.

- The lighting power density of each function room or place in the service area should conform to the requirements of GB 50034.

- The Service Area Operation Unit formulates the energy conservation, the water conservation, the environmental protection, the afforestation management system.

\subsubsection{Environmentally friendly}

- The construction land in the service area shall conform to the provisions of the Highway Engineering Project Construction Land Index (no. 124 of the construction bid [2011]) or the relevant land approval.

- The location, construction scale and function setting of the service area shall be in accordance with the local highway and service facilities planning.

- The sewage, noise and air pollution during the construction period shall meet the state regulations respectively.

\section{Concluding remarks}

The current standard of green service area in China --technical requirements for green transportation facilities evaluation Part 2: Green Service area (JT/T 1199.2-2018) in the framework of index evaluation system, it mainly draws on the 2014 edition of Green Building Evaluation Standard, in general, "green building evaluation standards" in the "four sections one environmental protection" as the core content.
"Green building evaluation standards" (GB/T50378-2019) from the original emphasis on "maximum conservation of resources (energy, land, water, materials), environmental protection" (four section one environmental protection) to "harmonious coexistence between man and nature" transformation, in accordance with the General Secretary Xi's basic policy of developing harmonious coexistence between man and nature in socialism with Chinese characteristics in the new era, this paper puts forward the higher requirement of "building of high quality that maximizes the harmonious coexistence between man and nature". As a kind of architecture, the transformation of green service area also puts forward new and higher requirements for the research and establishment of evaluation index and standard system of green service area.

In this paper, the evaluation standards of new and old green buildings are compared, and the existing evaluation system of Expressway Green Service area is deeply studied, this paper expounds the relationship between the existing Green Service area evaluation system and the new and old green building standards, and finally, combining the new green building evaluation standards and the actual evaluation work, advances the new Green Service area evaluation index frame, in order to guide the construction and evaluation of Green Service area of expressway better, the main body and key index of evaluation system should be constructed to supplement and perfect the relevant policy standard of green service area.

\section{References}

1. Chen Li. Brief analysis of green building connotation and evaluation [J]. Journal of Architecture, 2004, (3): $48 \sim 50$.

2. GB/T 50378-2006. Green Building Evaluation Standard [s]. BEIJING: China Construction Industry Press, 2006,5.

3. GB/T 50378-2014. Green Building Evaluation Standard [s]. BEIJING: China Construction Industry Press, 2014,10.

4. GB/T 50378-2019. Green building evaluation standard [s]. BEIJING: China Construction Industry Press, 2019,8.

5. JT/T 1199.2-2018. Green Transport Infrastructure Assessment-technical requirements-part 2: Green Service Areas [R]. Anhui Provincial Traffic Planning \& Design Institute Co., Ltd., Ministry of Transport of the People's Republic of China, Ministry of Transport of the People's Republic of China, Ministry of Transport, Ministry of Transport, Ministry of Transport. PUBLISHED: May 5,2018.

6. DB 34/t 3272-2018. Highway Green Service area construction guide. Anhui Communications Holding Group Co., Ltd., Ministry of Transport of the People's Republic of China, Anhui Planning and Design Research Institute Co., Ltd.. PUBLISHED: May 5,2018. 
7. Technical Guide for Green Highway Construction. Prepared by the Ministry of Transport of the People's Republic of China, Ministry of Transport of the People's Republic of China. BEIJING: People's Communications Press Co., Ltd., 2019,12.

8. Zhuang Yingchun. Green building and ground source heat pump system [J]. Journal of Architecture, 2004, (3): $48 \sim 50$. 